\title{
Swedish-Brazilian Cooperation in Aeronautics in Santa Catarina State
}

\author{
André L. M. de Oliveira ${ }^{1}$, Edemar Morsch Filho ${ }^{2}$, Amir A. M. Oliveira Jr. ${ }^{2}$, Talita S. Possamai ${ }^{3}$, Victor J. De Negri ${ }^{2}$ \\ ${ }^{1}$ Metrology and Instrumentation Center - Centers of Reference in Innovative Technologies, Florianópolis, Brazil \\ ${ }^{2}$ Department of Mechanical Engineering - Federal University of Santa Catarina, Florianópolis, Brazil \\ ${ }^{3}$ Department of Mobility Engineering - Federal University of Santa Catarina, Joinville, Brazil \\ E-mail: aeo@certi.org.br, edemar@labcet.ufsc.br, amir.oliveira@gmail.com, talita.possamai@ufsc.br, \\ victor.de.negri@ufsc.br
}

\begin{abstract}
In this article, the strategic view leading to the creation of a convergence center for aerospace technologies in the State of Santa Catarina, Brazil, the business and operation plans, as well as the predicted impacts in the state's economy are presented. Development and innovation are a result of a favorable ecosystem that nurtures the integration of technological creation, proof of concept and human resources. The transformation of new technologies in market products requires the close cooperation of $\mathrm{R} \& \mathrm{D}$ and academic institutions, tech companies and the market. This convergence of stakeholders is achieved by developing a common language and a sense of community, based on work and trust, built along the operation of a cycle, linking market demands to institutional offers, and multiplying the community efforts by cooperation. This is the ground, over which the SC2C.Aero, the Santa Catarina's Center of Convergence for Aerospace Technologies, has been rooted. The center has been configured as a network of tech groups aiming at supporting fast connections and R\&D\&I agreements. This article reviews the operational model that executes the center's key activities, such as the management of national and international agreements, customer and partner relationships, international matchmaking events, and a database mapping demands, offers and funding sources. The results achieved so far demonstrate the large acceptance this model received from both industry and R\&D\&I tech groups. These results have created visibility for the State of Santa Catarina and stimulated the expansion of the cooperation between Swedish and Brazilian institutions. Based on the center's strategic planning, five milestones are foreseen in the annual operation of SC2C.Aero that will support Santa Catarina as a top three destiny of investments from the aerospace sector in Brazil in the future.
\end{abstract}

Keywords: Technology Networks, Aeronautics, University-Industry Cooperation, Convergence Center

\section{Introduction}

The aerospace is a multifaceted sector, whose development requires diverse engineering specialties, a fast learning ecosystem with a capacity for fast growing, a network of technology and service providers, as well as a qualified work force. Santa Catarina fulfils these requirements. The state is home for three large public universities and more than a dozen community and private universities, more than thirty technology clusters and incubators, and public services and infrastructure that foster innovation and entrepreneurship. This scenario has resulted in estimated 15.5 billion Reals (3.7 billion Euros) of revenue from the technology sector in the state in 2017 , about $5.6 \%$ of the state gross product. The IT sector alone comprises more than 3,000 companies and 20,000 jobs in Santa Catarina [1].
The state has also been home of recent investments aiming at the aerospace sector, such as the recently inaugurated EMBRAER's office in Florianópolis; capital of Santa Catarina, the establishment of CERTI as an EMBRAPII Unit for Intelligent Systems; the cooperation of research groups from UFSC in joint projects with the University of Linkoping from Sweden and the company SAAB, as well as the cooperation with several Brazilian universities, such as ITA, UFMG and USP-São Carlos in several activities aiming at the technology transfer and spillover effects from the acquisition of the Gripen fighters by the Brazilian Defense Ministry [24]. The development of the FloripaSat, a CubeSat carrying payloads to measure effects of solar radiation on on-board electronics, in cooperation with the University of New South Wales (Australia) and the company NanoXplore, by a team of researchers from UFSC and private entrepreneurs; the inauguration in 2009 of the UFSC Joinville Mobility Center offering an undergraduate degree in Aerospace Engineering, 
and the creation by SENAI of the Innovation Institute in Embedded Systems in 2018, completing its regular offering of the Airplane Maintenance technical degree since 2009, are also important events that have strengthened aerospace development in the state.

This several initiatives moved the departments of Mechanical Engineering and Aerospace Engineering from the Federal University of Santa Catarina (UFSC) and the Centers of Reference in Innovative Technologies' Foundation (CERTI), with the support of the Research and Innovation Support Foundation of Santa Catarina State (FAPESC), to start actions in 2016 for the constitution of a Brazil-Sweden Cooperation Center. The main objective was to improve the quality and intensity of the interactions between companies, government and R\&D institutions. Secondary objectives were to propose topics for $R \& D$ and to provide support for the execution of research activities already in progress involving teams from both countries. It was a common understanding that cooperation among institutions, connecting skills and sharing existing infrastructures, is very effective way to achieve concrete results in shorter time and to optimize development costs [5].

In 2017, the center was created with its present name, the Santa Catarina's Center of Convergence for Aerospace Technologies, SC2C.Aero. The project focused on attracting public and private investments from the aerospace sector to Santa Catarina through collaborative work as a technology convergence center. It was configured as a network of technological R\&D\&I groups, with the mission of placing Santa Catarina as one of the top 3 states considering investments in the aerospace sector in Brazil. From 2018, this initiative is also supported by a project with the Ministry of Science, Technology, Innovation and Communications (MCTIC).

The SC2C.Aero is presently running its second annual cycle. In its present form, it aims to expand nationally and internationally through the resulting cooperation between Brazil and Sweden in the field of aerospace technologies, stronger since the Gripen purchase, as well as in other highly technological industrial sectors. It evolves in the perspective that a strong regional aerospace industry will result in extensive impacts in all areas of science and technology. The aerospace sector is technology-intensive and requires highly skilled labor. The investment in this sector is prone to create spillover opportunities to other sectors, such as IT, and result in a strong positive impact on the States' trade balance.

This article presents the key aspects of the design and operation of the SC2C.Aero, as well as, a report of its results up to now.

\section{Methodology}

In a worldwide context, other countries have already started initiatives to boost the aeronautical sector towards the next generations of aircrafts based on Technology Demonstrators, creating organizations to address the challenges of the sector. In US, the NextGen effort is responsible for modernization of air transportation system [6]. CleanSky is an European research and innovation program that aims to strength
European aero-industry collaboration, promote global leadership and competitiveness [7]. France has also worked to develop the technologies necessary to improve its environmental footprint and boost competitiveness through the CORAC committee by stimulating its members for future shape of aviation, consequently giving them a lead when a new program emerges [8]. Within the Strategic Research Agenda (SRA), from the Advisory Council for Aeronautics Research in Europe (ACARE), there is also important inspiration for the actuation of SC2C.Aero, which contemplates the integration of all stakeholders from this context to define the future shape of European aeronautics. Further, the society needs in aviation are translated and categorized in technological solutions to face the challenges of the field [9].

The work group from SC2C.Aero studied the main actions taken by those countries and identified the following trends: production of new aircraft with a noticeable reduction in the use of fuels, with drastic reduction of the noise level and emission of pollutants, coupled with strict safety and comfort standards.

\subsection{The proposal of the convergence center}

A preliminary model for the SC2C.Aero was advanced in 2017 from a grant of the Research and Innovation Foundation of the State of Santa Catarina (FAPESC) to build upon the initiatives between Brazil and Sweden in the aeronautical field. Encouraged by the Brazilian Ministry of Science, Technology, Innovation and Communication (MCTIC) in 2018, the focus of the center was amplified to cover R\&D\&I in aerospace in Brazil and international collaboration in general.

This initiative started by identifying the ongoing collaborations among academia, industry and govern in this field involving both countries. It was found that the aeronautical segment in Brazil and Sweden had been collaborating for at least 20 years in individual projects connected to different agents. A stronger connection of the whole chain (govern, industry and academia) was still missing despite the successful results of each individual cooperation. A new model was then identified with focus on the network of research groups combining efforts to a common goal - to increase the quality and impact of the interactions between companies, government and R\&D institutions.

This model aimed at a center able to converge efforts of different stakeholders. Under the context of the triple helix model (see Fig. 1), the stakeholders in the aerospace sector were identified as:

- Project executors: technical groups, members of the network, that are interested in the development of the market to sell their projects of R\&D\&I;

- Partners and project funders: companies of the aeronautical sector that invest in R\&D\&I projects and are interested in their sustainability and in the development of the segment;

- Influencers and funders: government agents, other networks and associations in the aeronautical sector, 
interested in the development of the sector and society in all its dimensions.

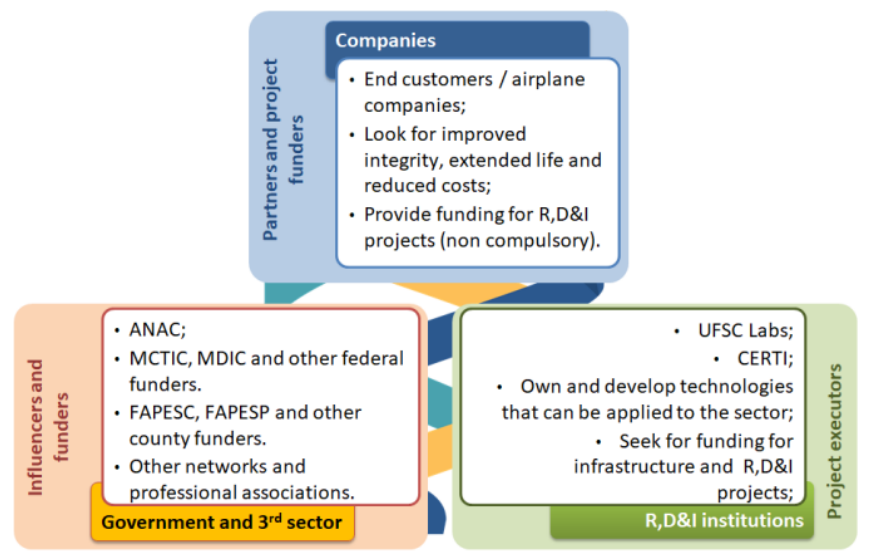

Figure 1: The stakeholders of the convergence center in a triple helix.

To better understand the stage where these three main agents cooperate for the success of an attractive environment for the aeronautical field, critical scenarios involving this initiative were studied based on a SWOT analysis, where the best strengths and weakness in the sector were balanced to predict the competences required for a solid convergence center. As result of the analysis, the management of stakeholders surfaced as the priority zero action for a center in this context. The central node of the entity should also support marketing strategies and a communications plan, develop a list of competences directed to the sector, as well as, test sites and simulation facilities, keep national and international cooperation up to date, provide storage, communication and processing facilities, customer database management, tracking of opportunities, matchmakings' meeting organization, update funding sources and advocate with public agents.

Based on the long run perspective for the project, formal guidelines for the establishment of a convergence center were stated as:

- Mission:

- To attract public and private investments from Aerospace Sector to the State of Santa Catarina through collaborative work as a technology convergence center.

- Vision:

- In 2030, the State of Santa Catarina will be on the top three states in Brazil considering the investments in the Aerospace Sector - and the network and its members will be organized as an important driver to keep this position.

- Short term goals:

- Inaugurate basic infrastructure facilities and hire management personnel by 2019;

- Contract five new projects with its members in the aerospace sector until 2020;

○ To reach sustainability of its operations by 2021 .

\subsection{Operation of SC2C.Aero}

The operation of the SC2C.Aero is based on attracting and connecting the stakeholders from the triple helix in annual cycles, where 5 milestones are foreseen (see Fig. 2): Demand research, Offer capacity, Matchmaking event, Contracting and Launch of projects. In this study, only the 3 initial steps of the annual cycle will be discussed in the following sections together with the main results of each one.

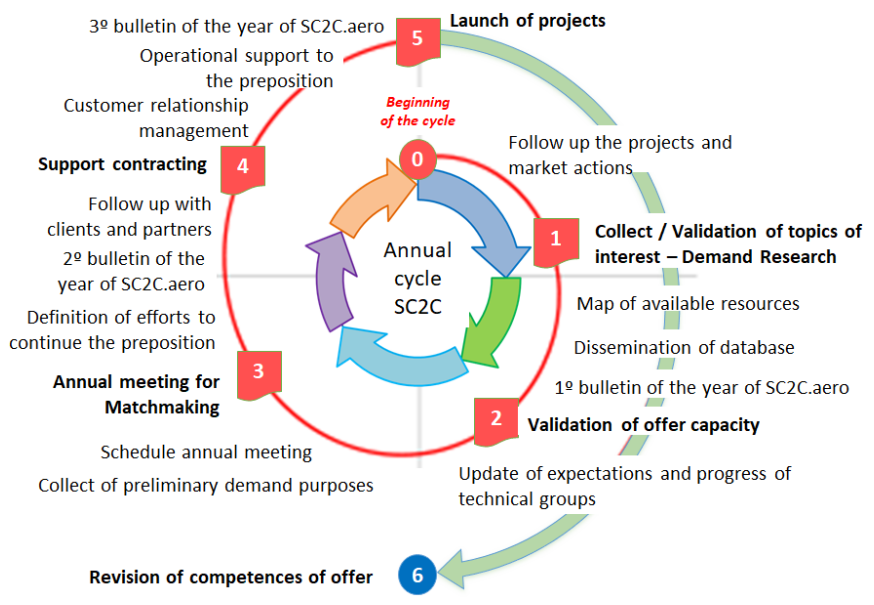

Figure 2: Annual cycle of SC2C.Aero.

\subsubsection{Demand research}

The demand research is the first milestone of the annual cycle of SC2C.Aero and has as main objectives to collect technological concerns from industry for a biennium (current and next year) and to create a networking with potential stakeholders. Secondary objectives are to disseminate the initiative and collect opinions to adjust the cooperation model of SC2C.Aero and to create motivation for academic research groups and stakeholders towards SC2C.Aero goals.

The group understood the need to use a common language among the players of the triple helix and the ASTERA taxonomy was chosen as a base system for communication [10]. This taxonomy divides the aeronautical areas as a first level and knowledge areas as second and third levels. In Fig. 3 the areas of first level are shown. Second and third levels become very specific and counts tens of items. It became the common language to organize the information received from the industry and academia by the Center of Convergence.

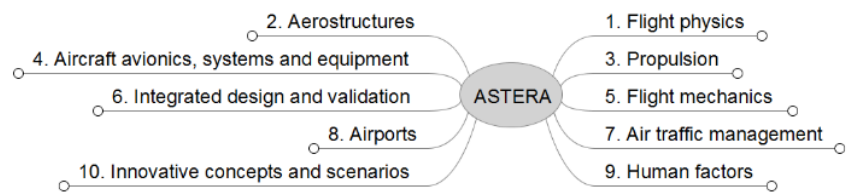

Figure 3: The first level of ASTERA taxonomy [10].

In order to collect the demand from companies, the SC2C.Aero work group focus answering the following question: What are the main concerns, or "pains", in the aerospace industry that can be developed as projects by SC2C.Aero?

The research to address this question follows a methodology characterized by its typology, population, sample and data. The research can be classified as descriptive conclusive [11]. 
The survey is qualitative because of its objectives and responses for the question, however some quantitative data may be collected to support the development of the project. In this research, the population are managers of $R \& D \& I$ in companies of the aerospace segment stationed in Brazil and legal representative authorities.

For the first cycle, executed in 2017 , the size of the sample was 14 companies and 2 federal ministries. Given the focus of that survey, time and cost limitations, companies located in the State of Santa Catarina, São José dos Campos in the State of São Paulo and representatives of the govern in Brasília were chosen. For that occasion, the sample size had 2 companies in Santa Catarina (WEGA Aircraft and Horus), 6 companies in São José dos Campos (Konatus, Embraer, Avibras, Akaer, Boeing, and Eleb), the Ministry of Defense and the Ministry of Science, Technology, Innovation and Communication.

The method and technique to collect data was the in situ research with application of face-to-face interview. The inperson meetings at companies and ministries were booked with the following agenda: Arrival and presentation/greetings (15 min), Presentation of the project and preliminary model of SC2C.Aero/gathering of opinions (15 min), Presentation of the objective and procedures $(5 \mathrm{~min})$, Collection of workable topics of interests $(25 \mathrm{~min})$.

The results of the interview for each company were later grouped and indexed following the ASTERA taxonomy, generating a highly valuable spreadsheet to be shared with the technical groups and partners members of SC2C.Aero. They included Company, Topic of interest or pain, Taxonomy and Theme (Education, Raw material, Process, Products and components, Technological services, Regulation). More than one company mentioned similar topics of interest, as well as technological issues and need of human resource programs.

\subsubsection{Offer capacity}

The next step and milestone of the annual cycle is the Offer capacity (see Fig. 2). This topic aims at collecting the offer capacity based on taxonomy and TRL. The secondary objectives include crossing of demand with offer through taxonomy, motivate the research groups to support the progress of the sector in Santa Catarina, develop marketing material and create a competence database model to be applied in cooperation with Sweden and other countries.

As mentioned above, ASTERA is the taxonomy for common language for topics of interest from industry. Moreover, the work group felt the need to measure the readiness level of each technical group in respect to the technologies they develop and adopted the Technology Readiness Levels (TRL) as a tool for the Offer Research. This scale has 9 levels to assess the maturity level of a given technology, where 1 is the lowest and 9 is the highest technology readiness level [12].

To collect the offer from Santa Catarina's groups, the research was structured to answer the following question: What are the highlight competencies and skills of interest of the aerospace industry that can be provided by the technical groups on SC2C.Aero?
Some of the R\&D\&I performance criteria analyzed are:

-Project history with the aerospace industry, which demonstrates the group's ability to provide strong solutions for the aerospace sector;

-Research infrastructure, including equipment and buildings;

-Existence of a specific research focus;

-Number of students in the group;

-Group leader entrepreneurship ability, related to publications, partners and customers.

The population of the research are the leaders of the groups that are members of SC2C.Aero. The size was 17 groups (14 from UFSC and 3 from CERTI). Leaders of the groups were invited to watch a presentation about the SC2C.Aero objectives and operational plan, their role in the triple helix, results from demand research and the Offer research. Later, a digital structured questionnaire was created and sent to the leaders of each group in the list.

In addition to the items mentioned by companies, the following questions were included in the form to favor the crossing of demand and offer capacity:

- Items of the ASTERA taxonomy that the lab can work nowadays, including the TRL;

- Example of projects (with companies), related or not with the aerospace sector, and the TRL reached;

- Facilities and competences to test and simulate aeronautical systems and products;

- The perspective for future by addressing the taxonomy and TRL that they would like to work with.

The results surveyed in this step were matched to the results of the demand survey/topics of interest.

\subsubsection{Matchmaking event}

After the demand and offer research, a matchmaking event took place to promote the matchmaking between demand and offer. The event was named Workshop of Santa Catarina's Convergence Center for Aerospace Technologies and is part of the annual cycle of operation of SC2C.Aero. Its objective is connecting companies, govern agencies and technology institutions in Brazil and Sweden in the aerospace sector. Bringing together official representatives from Sweden and Brazil, the connections between the two countries are further strengthened. The target audience are companies of the aerospace sector, technical groups of Santa Catarina, technology institutes focused in the aerospace segment in Brazil and Sweden, members of Santa Catarina state government and research foundation, as well as representatives of government and innovation supporting agencies in Brazil and Sweden.

The $1^{\text {st }}$ Workshop SC2C.Aero was held in May $3^{\text {rd }}$ and $4^{\text {th }}$, 2018. Topics presented and discussed were the SC2C.Aero results obtained from 2017 until the event, the perspectives and challenges in the sector, the established connections, the center members and next steps. Representatives from companies such as Embraer, Saab, ELEB, Glenair, Akaer, 
and several others attended the event. Representatives from the Brazilian and Swedish government as well as the academic institutions UFSC, LiU, ITA, SENAI, IFSC, and UFABC also participated. The workshop included speeches from CISB - Swedish-Brazilian Research and Innovation Centre, AEB- Brazilian Aerospace Agency, and InnovairSwedish Strategic Innovation Programme for Aeronautics.

\section{Results}

On the research demand, a total of 51 topics of interest were listed by companies, matching with 104 (including repeated) items of the taxonomy (see Fig. 4). Except for the item 8Airports, all other primary level of the taxonomy had at least one element mentioned by companies. The areas most cited were 2-Aerostructures, 4-Aircraft avionics, systems and equipment and 6-Integrated design and validation, respectively.

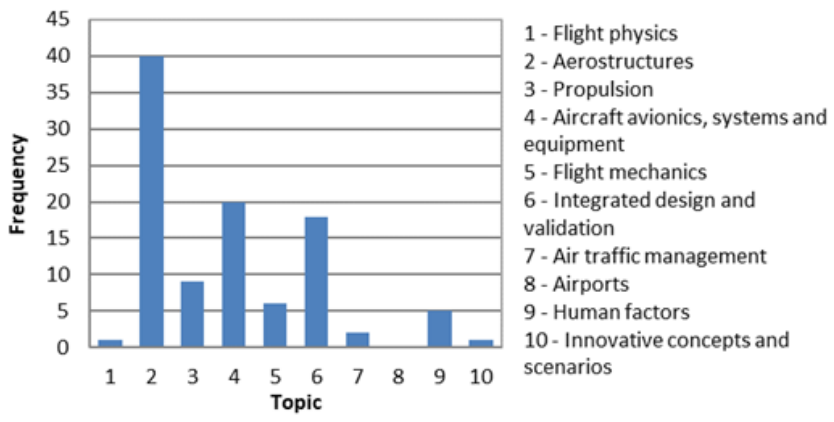

Figure 4: Histogram with topics of interest organized in the ASTERA taxonomy.

In the offer demand, a total of 11 groups answered positively and shared their information to form the offer capacity of SC2C.Aero. A total of 51 professionals were reached in the survey including faculty, post-docs, doctor and master's students. Regarding the topics of interest in the ASTERA taxonomy, a total of 75 items were listed by the groups. By observing the classification of demand or topics of interest (demand research), a good superposition of offer and demand was found, creating diverse opportunities for project (see Fig. $5)$.

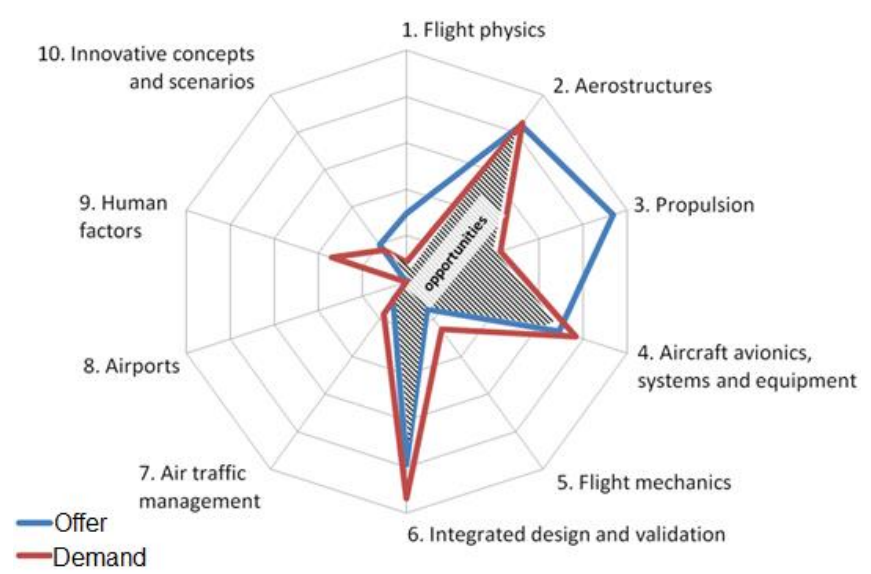

Figure 5: Crossover of topics of interest and offer with data collected in 2017.
Except in Flight Physics and Propulsion, where there is greater offer capacity than topics of interest, the other classifications are quite coherent and coincident. There are even opportunities of connection with other groups of UFSC in areas without mapped competencies (like Human Factors), while Aerostructures, Aircraft avionics and Integrated design and validation show capacities already mapped to meet the demands of the aeronautical sector. These databases are considered dynamic as new cycles begin, for both constant update of technical groups and introduction of new groups or international cooperation, creating a solid base to be explored in the solutions of demand of the sector.

\section{Conclusions}

After the consolidation period of SC2C.Aero, estimated as 3 years, the center should opt for professional network with permanent connection, and not through research fellowships, since the work of development ends but the operation has to be handled with continuity. At this moment, a new analysis and revision of this plan is under way.

The matchmaking event, part of the annual operational cycle, is a platform for marketing of competencies found in the State of Santa Catarina that are of value for competitive companies of the aerospace segment. Once this value is recognized, the companies will search for and find qualified human resources in the state, resulting in more jobs, income and wealth.

The deadlines for submission of funding sources must be monitored, but also directly handled with the agents, looking for the recognition of the importance of SC2C.Aero for the involved institutions, for the state and for the country.

The SC2C.Aero just completed its second year of existence. In its present form, it impacts not only the field of aerospace technologies, but also other highly technological industrial sectors. It will evolve in the perspective that a strong regional aerospace industry will result in extensive impacts in all areas of science and technology. The investment in the aerospace sector is prone to create spillover opportunities to other sectors, such as IT, and result in a strong positive impact on the state's trade balance, economic and social indicators.

\section{Acknowledgments}

This project has been financially supported by FAPESC Research and Innovation Foundation of Santa Catarina State and MCTIC - The Brazilian Ministry of Science, Technology, Innovation and Communications. The cooperation with SARC - Swedish Aeronautical Research Center and CISB Swedish-Brazilian Research and Innovation Centre are greatly appreciated.

\section{References}

[1] Federação das Indústrias do Estado de Santa Catarina: Santa Catarina em Dados. Available at https://www.observatoriofiesc.com.br/sc-em-dados

[2] DE NEGRI, V. J.; OLIVEIRA, A. A. M. de; SCHNEIDER, C. A.; MANTOVANI, T.; PEREIRA, J. 
C. C.; SALMORIA, G. V.; FREDEL, M. C.; DONATELLI, G. D.; SOETHE, V. L.; AL-QURESHI, H. A.; PEREIRA, R. S. F. Caracterização das competências no estado de Santa Catarina para o setor aeronáutico, 2013.

[3] Deiaco, E., Ek, I., Román, E. Nurturing spillover from the Industrial Partnership between Sweden and Brazil a case study of the Gripen project. Report 2016/106. Available at www.growthanalysis.se.

[4] Estudo Prospectivo Aeronáutico ABDI: 17/02/11 5. Industria Aeronáutica - ABDI: 12/11/10 6. Programa Demonstrativo para Inovacao em Cadeia Produtiva Selecionada Industria Aeronáutica Brasileira Serie Documentos Técnicos - CGEE set/2014.

[5] SC2C.Aero: SC2C.Aero. Available at https://sc2c.ufsc.br/

[6] Federal Aviation Administration: NextGen implementation plan. Washington,2012.

[7] Clean sky governing board: Clean sky annual implementation plan 2010. Bruxelas, 2010.

[8] Corac: Proposition sectorielle de Charte d'Organisation et de Gouvernance des plataformes de demonstration technologique proposées par le secteur aéronautique dans le cadre du pro-gramme d'investissements d'avenir. Available at http://www.aerorecherchecorac.com

[9] ACARE: Strategic Research Agenda, Volume 1. Available at: ww.acare4europe.org/sites/ acare4europe.org/files/document/volume1.pdf

[10]EASN: Aeronautical research \& technology areas. Available at https://easn.net/research-technology-areas/

[11] Frauze N. Mattar: Pesquisa de marketing. 4th. Ed. São Paulo: Editora Atlas, 2007.

[12]NASA: Technology Readiness Level. Available at https://www.nasa.gov/directorates/heo/scan/engineering /technology/txt_accordion1.html 